\title{
Experimental study on the microreactor-assisted synthesis of phosphinic chlorides with different steric hindrance
}

Aleksandra Jasiak, ${ }^{[a]}$ Krzysztof Owsianik, ${ }^{[a]}$ Bartłomiej Gostyński, ${ }^{[a]}$ Grażyna Mielniczak, ${ }^{[a]}$ Christian V. Stevens ${ }^{[c]}$ and Józef Drabowicz ${ }^{*[a],[b]}$

[a] B. Sc., A, Jasiak, dr. K. Owsianik, dr. B. Gostyński, dr. G. Mielniczak and prof. J. Drabowicz Department of Organic Chemistry

Centre of Molecular and Macromolecular Studies, Polish Academy of Sciences

Sienkiewicza 112, 90-363 Łódż, Poland

E-mail: ajasiak@cbmm.lodz.pl

Homepage: www.cbmm.lodz.pl

[b] Prof. J. Drabowicz

Institute of Chemistry

Jan Długosz University in Częstochowa

Armii Krajowej 13/15, Częstochowa 42-201, Poland

E-mail: draj@cbmm.lodz.pl

[c] Prof. C. V. Stevens

Department of Green Chemistry and Technology, Faculty of Bioscience Engineering, Ghent University, Campus Coupure, Coupure Links 653, 9000 Gent, Belgium

E-mail: Chris.Stevens@UGent.be

Abstract: An efficient and catalyst-free method for the preparation of optically active and racemic monosubstituted $t$-butyl phosphinic chlorides ${ }^{\mathrm{t}} \mathrm{BuRP}(\mathrm{O}) \mathrm{Cl}$ under flow conditions was reported. A variety of mono $t$-butyl substituted phosphinic chlorides were obtained using this protocol starting from the corresponding phosphine oxide and one equivalent of carbon tetrachloride (CAUTION: hepatotoxic) with reasonable residence times (25-125 min.) and excellent conversions (up to $99 \%$ ). The asymmetric reaction conducted in a glass microreactor chip with an internal volume of $250 \mu \mathrm{L}$ leads to the corresponding chloride with $96 \%$ enantiomeric excess. It is significant that the protocol works effectively when the phosphine oxide has one bulky group such as $t$-butyl, which prevent the formation of undesired products. The steric hindrance is proven to be important for the stabilization of the $\mathrm{P}-\mathrm{Cl}$ products. The key results were compared with the results obtained in batch conditions and it can be concluded that the flow method provides a sustainable, efficient alternative to the existing methods for the preparation of phosphinic chlorides. The isolation of the reaction products is straightforward because of the lack of any additives and the high purity of the obtained products. The results of the asymmetric reaction and the computational studies suggest that the reaction occurs through a mechanism involving a pentacoordinated phosphorus TS, with the apical positions occupied by the incoming $\mathrm{CCl}_{3}{ }^{-}$nucleophile and the $t$-butyl group.

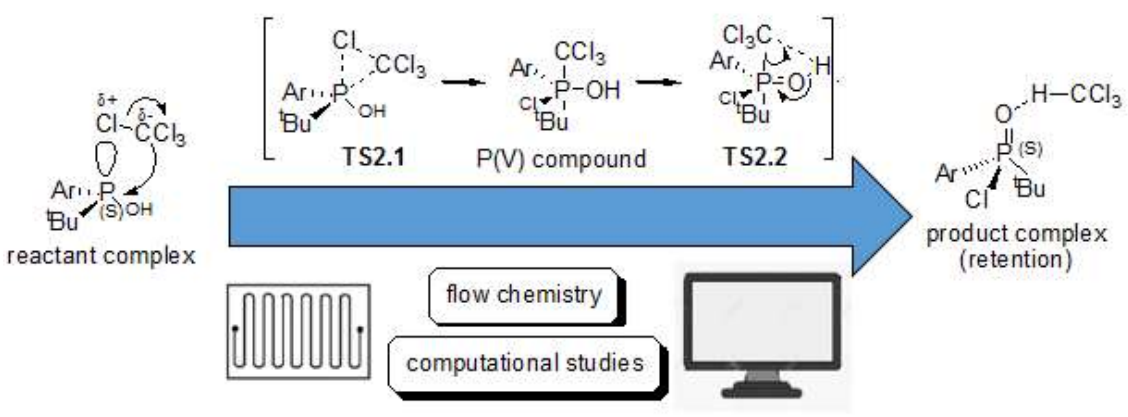

\section{Introduction}

Compounds of the general formula $\mathrm{RR}^{\prime} \mathrm{P}(\mathrm{O}) \mathrm{Cl}(1)$ are among the most useful intermediates in organophosphorus chemistry, especially in the synthesis of attractive precursors of phosphines such as tertiary phosphine oxides (TPOs) ${ }^{[1-2]}$, and organophosphorus acid derivatives. ${ }^{[3-4]}$ Such important chemical entities are widely utilized in organic synthesis ${ }^{[5-8]}$ as ligands for metal-catalysis, organocatalysts ${ }^{[9-10]}$, advanced functional materials [11], and are useful chiral auxiliaries for asymmetric synthesis ${ }^{[12]}$ as well as exhibiting diverse biological activities ${ }^{[13-18]}$. Sterically congested derivatives constitute a separate class and are of particular interest: 1 ) in catalysis because of their enhanced ability 
to induce enantioselectivity in various reactions, 2) as inhibitors of side reactions, 3) as effective stabilizing factor of reactive compounds, 4) as strong factors affecting the regioselectivity of the reactions. Our attention was focused on the synthesis of reactive pentavalent tetracoordinated organophosphorus chlorides ${ }^{\mathrm{B}} \mathrm{BuRP}(\mathrm{O}) \mathrm{Cl}$ from easy accessible secondary phosphine oxides (SPOs). It is known that SPOs, phosphonates and phosphinates are rearranged to their corresponding acid chlorides by treatment with different chlorinating agents $\left(\mathrm{CCl}_{4}{ }^{[19-20]}, \mathrm{CCl}_{4} /\right.$ base ${ }^{[21]}, \mathrm{CHCl}_{3} / \mathrm{base}^{[22]}, \mathrm{CuCl}_{2}$ ${ }^{[23]}, \mathrm{PhICl}_{2}{ }^{[24]}, \mathrm{Cl}_{2}{ }^{[25]}$, oxalyl chloride ${ }^{[26]}$, chloramines ${ }^{[27]}, \mathrm{TCICA}{ }^{[28]}, \mathrm{NCS}{ }^{[29]}$. Among the previously mentioned compounds, $\mathrm{CCl}_{4}$ appears to be the most convenient and available reagent (CAUTION: hepatotoxic!). F. R. Atherton and A. R. Todd first discovered it in 1945 and its reaction is one of the most characteristic reactions of diesters of $\mathrm{H}$-phosphonic acid [30]. This reaction takes place in the presence of a base and is a route for the oxidation of dialkyl $\mathrm{H}$-phosphonates to the highly reactive dialkyl chlorophosphates [31]. However, the synthesis of sterically congested variations, such as those containing a tert-butyl functionality, are rather limited by long reaction times, high temperatures, the use of supporting additives and therefore still remains a significant challenge ${ }^{[32]}$. This prompted us to evaluate the reaction of phosphine oxides with $\mathrm{CCl}_{4}$ in the absence of base, using continuous flow in order to develop a practical and efficient relevant procedure. Microreactor technology is also very well suited to deal with hazardous chemicals such as carbon tetrachloride in order to reduce risks (Add reference: M. Movsisyan, E.I.P. Delbeke, J.K.E.T. Berton, C. Battilocchio, S.V. Ley, C.V. Stevens, Chem. Soc. Rev., 45, $4892-4928$ (2016). ).

Preliminar research in batch has revealed that conversion of tert-butylphenylphosphine oxide only occurs at room temperature in carbon tetrachloride after a long time and with a low yield [19]. Inspired by this, we carried out a series of continuous flow experiments, including asymmetric ones, between carbon tetrachloride and various secondary phosphine oxides containing a tert-butyl substituent and testing different reaction conditions. The halogenation reactions were performed efficiently in miniaturized microfluidic devices, in order to exclude the use of any additives. Moreover, the lower consumption of chemicals and solvents in such devices results in both ecological and economic benefits ${ }^{[33]}$. Herein, we present a novel approach to explore this enabling technology, which offers a new route to produce phosphinyl chlorides which is hardly reachable with conventional batch procedures.

Unlike the A-T reaction with $\mathrm{CCl}_{4}$ in the presence of an amine, the mechanism without base is studied very seldomly. As far as we know, two fundamentally different suggested literature mechanisms for different phosphine oxides and chalcogenides were considered. They show that tetrachloromethane can lead to the generation of a chloronium ion to act as electrophile (Scheme 1, path a) ${ }^{[19,34]}$ or to a chloride anion to act as nucleophile (path b) ${ }^{[20]}$. Ab initio calculations, using even moderate levels of theory, could shed some light on energetics and possible mechanistic routes of this chlorination reaction.

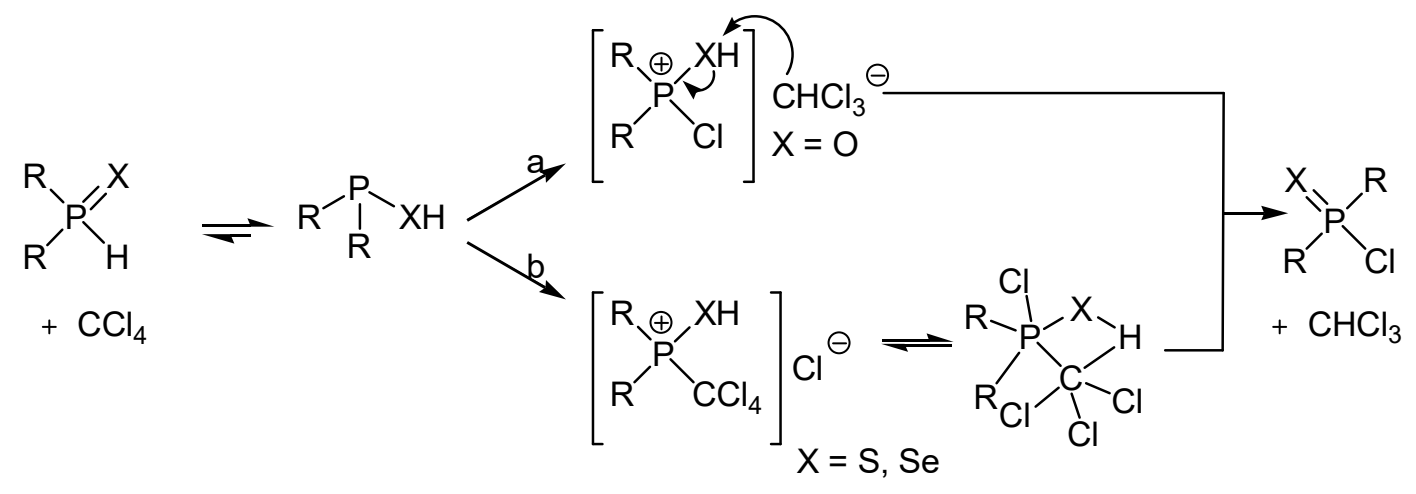

Scheme 1. Two different proposed reaction mechanisms of phosphine oxides and chalcogenides with tetrachloromethane.

(Please adjust; in a: the anion should be $\mathrm{CCl} 3$, not $\mathrm{CHCl}$; in b: the substituent on $\mathrm{P}$ should be $\mathrm{CCl} 3$, not $\mathrm{CCl} 4$ )

\section{Results and Discussion}


A continuous -flow setup was used to investigate different conditions for the transformation of secondary phosphine oxides 1-3 into the corresponding phosphonic chlorides 4-6 (scheme 2).

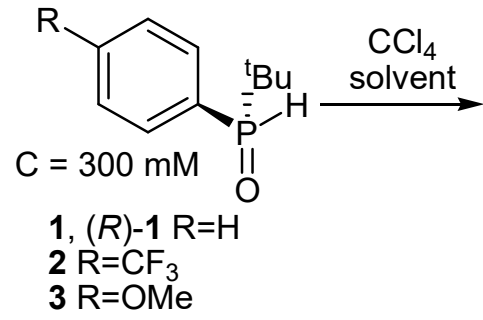

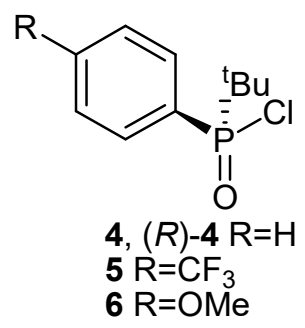

Scheme 2. Chlorination of phosphine oxides 1-3.

A screening was carried out to evaluate the effect of different solvents, temperature, residence time as well as the substituent on the phenyl ring for the synthesis of chlorides 4-6. For the transformation of the secondary phosphine oxides 1-3 into the desired products, two separate syringe pumps were used to introduce a solution of the phosphine oxides $(300 \mathrm{mM})$ and the carbon tetrachloride. In a first set-up, 1 equiv. of carbon tetrachloride was used, whereas in the second set-up a solution of pure $\mathrm{CCl}_{4}$ (35 equiv.) was pumped into a microreactor chip of $250 \mu \mathrm{l}$ volume via double T-mixer (scheme 3 (a)). The reaction mixture was collected in a flask and the product was isolated conveniently by immediate evaporation under a reduced pressure. Reactions in $\mathrm{CCl}_{4}$ were carried out using a solution of compounds 1-3 in tetrachloromethane $(150 \mathrm{mM})$ which was pumped directly through the flow reactor via a single syringe pump (scheme 3 (b)).

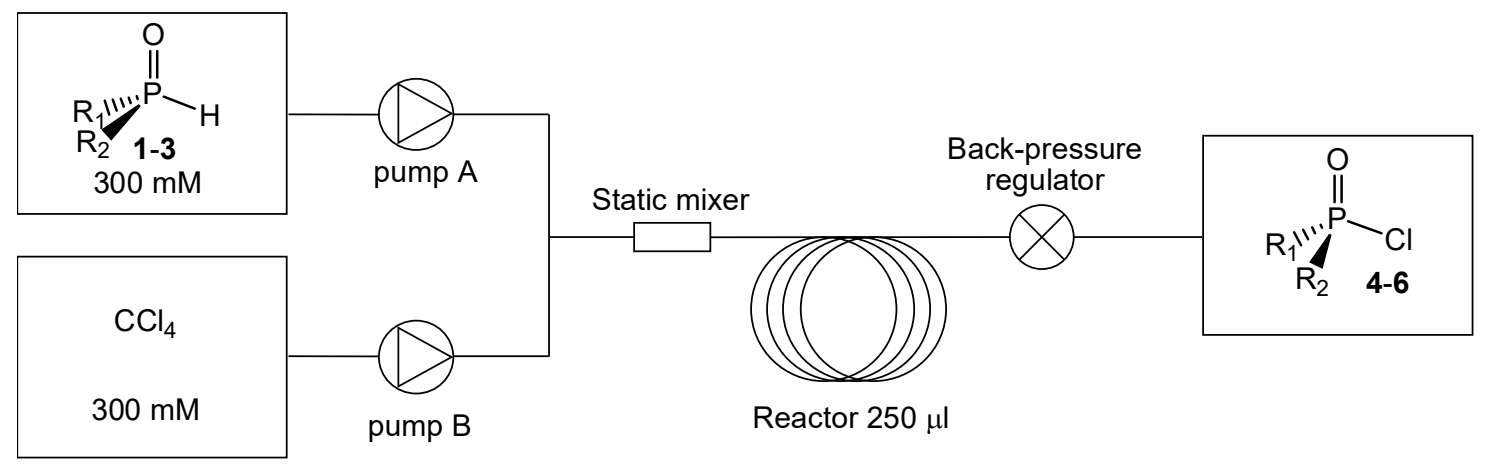

(a)

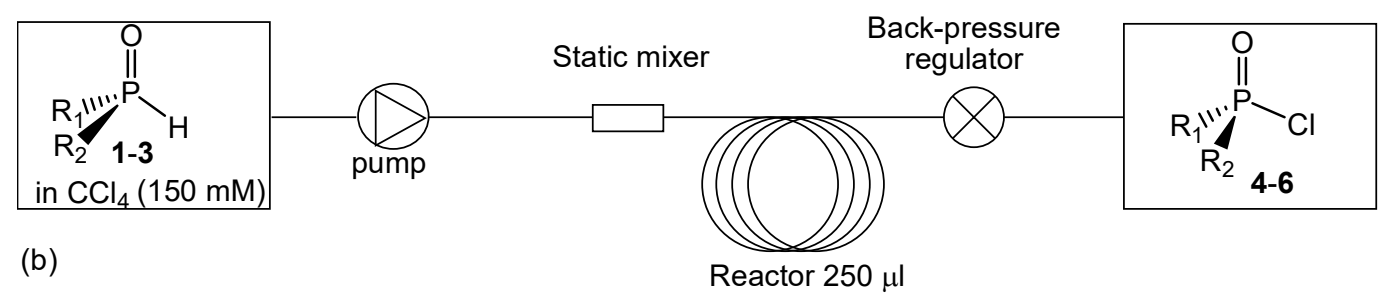

Scheme 3. Schematic representation of the continuous flow setup; a) with two separate syringe pumps and $b$ ) with one single syringe pump.

In one of our previous publications, the first example of the AT-like reaction in the absence of base was described [19]. It was demonstrated that (-)-(S)-tert-butylphenylphosphine oxide leads a after long time $(75 \mathrm{~h})$ at room temperature in tetrachloromethane to the formation of the corresponding chloride $(R)-\mathbf{4}$ with a conversion of $90 \%$ and $42 \%$ ee (table 1 , entry 2$)^{[19]}$. This result encouraged us to apply this procedure to the reaction, initially, adopting the batch conditions. Our first experiment at room 
temperature showed that a $90 \%$ conversion of rac- 1 could be achieved with tres of 62 min. To improve this result, other conditions were tested using this phosphine oxide. The reactions were carried out until complete transformation of 1-3 had occurred, or until the appearance of hydrolysis products.

Table 1. Key experiments in the optimization of the chlorination of phosphine oxides 1-3 to phosphinic chlorides 4-6 under continuous flow and batch conditions.

\begin{tabular}{|c|c|c|c|c|c|c|}
\hline \multicolumn{5}{|c|}{ Flow conditions ${ }^{a}$} & \multicolumn{2}{|c|}{ Batch conditions ${ }^{a, d}$} \\
\hline entry & comp. & Solvent & $\begin{array}{c}\text { conditions } \\
\left(t_{\text {res }}(\mathrm{min} .),\right. \\
\text { temp.) }\end{array}$ & conv. (\%) & $\begin{array}{c}\text { conditions } \\
\text { (time (min.), temp.) }\end{array}$ & conv. (\%) \\
\hline 1 & 1 & $\mathrm{CCl}_{4}^{\mathrm{b}}$ & $25,100^{\circ} \mathrm{C}$ & 88 & $420,77^{\circ} \mathrm{C}$ & $\geq 99$ \\
\hline 2 & 1 & $\mathrm{CCl}_{4}^{\mathrm{b}}$ & $62,25^{\circ} \mathrm{C}$ & 95 & $4500,25^{\circ} \mathrm{C}^{[19]}$. & $90^{\text {lit }}$ \\
\hline 3 & 1 & $\mathrm{CH}_{2} \mathrm{Cl}_{2}$ & $25,100^{\circ} \mathrm{C}$ & 55 & $240,40^{\circ} \mathrm{C}$ & 9 \\
\hline 4 & 1 & $\mathrm{MeCN}$ & $25,100^{\circ} \mathrm{C}$ & 74 & $90,60^{\circ} \mathrm{C}$ & 46 \\
\hline 5 & 1 & toluene & $25,100^{\circ} \mathrm{C}$ & $\geq 99$ & \multirow{2}{*}{$180,100^{\circ} \mathrm{C}$} & \multirow{2}{*}{$\begin{array}{c}\geq 99, \\
\mathrm{ee}=93 \%\end{array}$} \\
\hline 6 & $(R)-1$ & toluene & $25,100^{\circ} \mathrm{C}$ & $\geq 99$, ee $=96 \%$ & & \\
\hline 7 & 1 & toluene $^{c}$ & $25,110^{\circ} \mathrm{C}$ & $\geq 99$ & $420,110^{\circ} \mathrm{C}$ & $\geq 99$ \\
\hline 8 & 2 & $\mathrm{CCl}_{4}^{\mathrm{b}}$ & $25,100^{\circ} \mathrm{C}$ & 84 & \multirow{2}{*}{$420,77^{\circ} \mathrm{C}$} & \multirow{2}{*}{88} \\
\hline 9 & 2 & $\mathrm{CCl}_{4}^{\mathrm{b}}$ & $42,100^{\circ} \mathrm{C}$ & 90 & & \\
\hline 10 & 2 & $\mathrm{CH}_{2} \mathrm{Cl}_{2}$ & $25,100^{\circ} \mathrm{C}$ & 42 & $480,40^{\circ} \mathrm{C}$ & 14 \\
\hline 11 & 2 & $\mathrm{MeCN}$ & $42,100^{\circ} \mathrm{C}$ & 83 & $480,60^{\circ} \mathrm{C}$ & 6 \\
\hline 12 & 2 & toluene & $25,100^{\circ} \mathrm{C}$ & $\geq 99$ & $180,110^{\circ} \mathrm{C}$ & $\geq 99$ \\
\hline 13 & 2 & toluene $^{\mathrm{c}}$ & $25,110^{\circ} \mathrm{C}$ & $\geq 99$ & $240,110^{\circ} \mathrm{C}$ & 21 \\
\hline 14 & 3 & $\mathrm{CCl}_{4}^{\mathrm{b}}$ & $25,100^{\circ} \mathrm{C}$ & $\geq 99$ & $90,77^{\circ} \mathrm{C}$ & $\geq 99$ \\
\hline 15 & 3 & $\mathrm{CH}_{2} \mathrm{Cl}_{2}$ & $25,100^{\circ} \mathrm{C}$ & 36 & $300,40^{\circ} \mathrm{C}$ & 18 \\
\hline 16 & 3 & $\mathrm{MeCN}$ & $25,100^{\circ} \mathrm{C}$ & 88 & $720,60^{\circ} \mathrm{C}$ & 56 \\
\hline 17 & 3 & toluene & $25,120^{\circ} \mathrm{C}$ & 88 & \multirow{2}{*}{$90,100{ }^{\circ} \mathrm{C}$} & \multirow{2}{*}{$\geq 99$} \\
\hline 18 & 3 & toluene & $42,100^{\circ} \mathrm{C}$ & $\geq 99$ & & \\
\hline 19 & 3 & toluene $^{\mathrm{c}}$ & $42,130^{\circ} \mathrm{C}$ & $\geq 99$ & $120,100^{\circ} \mathrm{C}$ & 97 \\
\hline
\end{tabular}

${ }^{a}$ reaction conditions: 35 equiv. of $\mathrm{CCl}_{4}(\mathrm{v} / \mathrm{v}$ : $1: 1),{ }^{\mathrm{b}} \mathrm{CCl}_{4}$ as solvent, 1-3 $(\mathrm{C}=150 \mathrm{mM}),{ }^{\mathrm{c}}$ reaction with 1 equiv. of $\mathrm{CCl}_{4}(\mathrm{C}=300 \mathrm{mM}), \mathbf{1 - 3}(\mathrm{C}=300 \mathrm{mM}){ }^{\mathrm{d}}{ }^{\text {batch }}$ conditions: $1-3(\mathrm{C}=150 \mathrm{mM})$.

By using a back pressure regulator (BPR) to achieve the pressurization of superheating of solvents, we were able to perform the reactions in low-boiling point solvents such as dichloromethane at higher temperatures. And thus, the reaction in DCM at $100{ }^{\circ} \mathrm{C}$ during 25 min. of residence time, gave an average conversion of tert-butylphenylphosphine oxide of $55 \%$. This result is much better than the one obtained under traditional conditions at the boiling point of the solvent, because significant longer reaction times (240 min.) were required at $40{ }^{\circ} \mathrm{C}$ to obtain the corresponding product 4 with only $9 \%$ conversion (entry 3 ). The influence of a more polar solvent as acetonitrile was also evaluated for these reactions. It was found that increasing the temperature to $100^{\circ} \mathrm{C}$ enhanced the yield of the halogenation to $74 \%$. (entry 4). A quantitative conversion was obtained under flow conditions using toluene as a solvent in a short period of time (25 minutes) at $100{ }^{\circ} \mathrm{C}$ with an excess of $\mathrm{CCl}_{4}$ (entry 5). With the optimized reaction conditions in hand, the reaction with the optical active phosphine oxide $(R)-1$ was carried out. Despite the high temperature, racemization did not occur and the chiral chloride (S)-4 was obtained with a high enantioselectivity of $96 \%$ ee (entry 6 ). To limit the amount of the perchlorinated reagent, the reaction with 1 equiv. of $\mathrm{CCl}_{4}$ in toluene was performed and the quantitative conversion was obtained when the temperature was raised ten degrees to $110^{\circ} \mathrm{C}$ (entry 7 ). 
Next, the reactivity of the substituted phenyl ring analogues of 1 , such as tert-butyl-paratrifluoromethylphenylphosphine oxide (2) and tert-butyl-para-methoxyphenylphosphine oxide (3), were tested in the same flow setup and in batch.

First, we examined the effect of different solvents and conditions on the phosphine oxide 2 conversion. To get a satisfying amount of product $5(88 \%)$ in batch, the reaction was heated in $\mathrm{CCl}_{4}$ at reflux for 720 min. To obtain a similar result in flow, the reaction had to be performed for a residence time of 42 min. (entry 9). Similar to oxide 1, in DCM, moderate conversions were obtained both under flow and batch conditions (entry 10), while an excellent result was achieved at $100^{\circ} \mathrm{C}$ for a residence time of 25 minutes in toluene using an excess of $\mathrm{CCl}_{4}$ (entry 12). When 1 equiv. of chlorinating agent was used, the temperature needed to be raised by 10 degrees in order to obtain a quantitative conversion. A similar result was unreachable under batch conditions with a $21 \%$ conversion after $240 \mathrm{~min}$. at $110^{\circ} \mathrm{C}$. Both in this case and in previous cases regarding tert-butyl-para-trifluoromethylphenylphosphine oxide (6), the comparison of the flow method with the traditional batch one is particularly favourable.

The transformation of tert-butyl-para-methoxyphenylphosphine oxide (3) was evaluated in the same flow setup. Using $\mathrm{CCl}_{4}$ as solvent afforded a quantitative conversion under mild conditions $\left(25 \mathrm{~min} ., 100{ }^{\circ} \mathrm{C}\right)$ (entry 14). Somewhat surprisingly, a similar result was obtained under batch conditions at the reflux temperature $\left(77^{\circ} \mathrm{C}\right)$ after $1,5 \mathrm{~h}$. Also, acetonitrile perform well as solvent in this comparison. After 25 min. at $100{ }^{\circ} \mathrm{C}$, the conversion was $88 \%$ and the differences in the reaction time were significant compared to the standard conditions. The exceptionally long reaction time in this case results from the lower temperature, which is the maximum that can be achieved under batch conditions. Adding electrondonating group such as a methoxy group to the phenyl ring did not accelerate the reaction in toluene under flow conditions. In this case, the reaction requires a longer retention time of $42 \mathrm{~min}$. to achieve a quantitative conversion. A lower temperature of $100{ }^{\circ} \mathrm{C}$ is enough when an excess of $\mathrm{CCl}_{4}$ was used in toluene, whereas in order to limit the amount of the reagent to 1 equiv., the flow temperature needed to be $130^{\circ} \mathrm{C}$. The excess tetrachloromethane can however be easily recuperated by simple distilation and can be reused.

In view of these results, it seemed interesting to study similar reactions under flow conditions with symmetric analogues of compounds 1-3: more sterically hindered di-tert-butylphosphine oxide (7) and the more reactive diphenylphosphine oxide (9).

The current synthetic methods producing the sterically demanding chloride $\mathbf{7}$ in high purity are mostly based on the oxidation of the corresponding highly reactive chlorophosphines and are therefore inconvenient to use [35]. The reaction of oxide 7 with 1 equiv. of $\mathrm{CCl}_{4}$ was carried out in dichloromethane and toluene or in carbon tetrachloride as a solvent, in the temperature range from 60 to $150^{\circ} \mathrm{C}$ (Table 2).<smiles>CC(C)(P)Br</smiles>

7

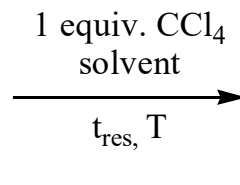<smiles>CC(C)(C)P(=O)(Cl)Br</smiles>

8

Table 2. Key experiments in the optimization of the continuous flow reaction conditions for the synthesis of di-tert-butylphosphinic chloride (7).

\begin{tabular}{|c|c|c|c|c|}
\hline entry & solvent & $\mathrm{t}_{\text {res }}{ }^{a}(\mathrm{~min})$. & temp. $\left({ }^{\circ} \mathrm{C}\right)$ & conv. (\%) \\
\hline 1 & $\mathrm{CH}_{2} \mathrm{Cl}_{2}$ & 25 & 100 & $\leq 1$ \\
\hline 2 & $\mathrm{CH}_{2} \mathrm{Cl}_{2}$ & $125^{b}$ & 60 & $\leq 1$ \\
\hline 3 & $\mathrm{CCl}_{4}$ & 25 & 100 & $\leq 1$ \\
\hline 4 & $\mathrm{CCl}_{4}$ & 125 & 100 & $\leq 1$ \\
\hline
\end{tabular}




\begin{tabular}{|c|c|c|c|c|}
\hline $\mathbf{5}$ & toluene & 25 & 150 & 42 \\
\hline $\mathbf{6}$ & toluene & 125 & 150 & $\geq 99$ \\
\hline \multicolumn{2}{|c|}{${ }^{\text {at }}$ res - residence time, ${ }^{\mathrm{b}}$ estimated on the basis of ${ }^{1} \mathrm{H}$ and ${ }^{31} \mathrm{P}$ NMR. } \\
\hline
\end{tabular}

Heating the reaction mixture at $60^{\circ} \mathrm{C}$ in $\mathrm{CH}_{2} \mathrm{Cl}_{2}$ or at $100{ }^{\circ} \mathrm{C}$ in $\mathrm{CCl}_{4}$ resulted in a conversion of less than $1 \%$ product, even if a residence time of 125 min was applied (Table 2, entries 1-5). The best result $(\geq 99 \%)$ was obtained in toluene at $150{ }^{\circ} \mathrm{C}$ and a residence time of 125 min (Table 2, entry 6). In the batch procedure, a total reaction time of two days and an elevated temperature over $100{ }^{\circ} \mathrm{C}$ were not sufficient to obtain chloride 7 . On the one hand, high steric hindrance requires to apply quite drastic reaction conditions in order to obtain the product, on the other, drastic conditions lead to degradation and thus prevent obtaining the product in high yield. This was observed carrying out flow reactions with substrates such as diethyl- and diisopropylphosphine oxide. In both cases, the corresponding acids or mixtures of various compounds were obtained as product. These results are in accordance with the literature data describing the disproportionation reactions of alkyl phosphine oxides to the acids in the presence of even small amounts of chlorides formed during the reaction [36].

The reaction of diphenylphosphine oxide with 1 equiv. of $\mathrm{CCl}_{4}$ was carried out in toluene which proves to be the most suitable solvent in the previous attempts and in the temperature range from 80 to $150^{\circ} \mathrm{C}$ (Table 3).<smiles>O=P(c1ccccc1)(c1ccccc1)c1ccccc1</smiles>

9

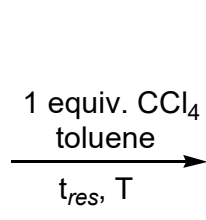<smiles>[13CH3]P([13CH3])(=O)C1=CCCC=C1</smiles>

10<smiles>O=P(O)(c1ccccc1)c1ccccc1</smiles>

11<smiles>O=P(OP(=O)(c1ccccc1)c1ccccc1)(c1ccccc1)c1ccccc1</smiles>

12

Table 3. Key experiments in the optimization of the continuous flow reaction conditions for the chlorination of diphenylphosphine oxide (9).

\begin{tabular}{|c|c|c|c|c|c|c|}
\hline entry & $\mathrm{t}_{\text {res }}{ }^{\mathrm{a}}(\mathrm{min})$. & $\begin{array}{c}\text { temp. } \\
\left({ }^{\circ} \mathrm{C}\right)\end{array}$ & $\mathbf{9}^{\mathrm{b}}(\%)$ & $10^{\mathrm{b}}(\%)$ & $\mathbf{1 1}^{\mathrm{b}}(\%)$ & $\mathbf{1 2}^{\mathrm{b}}(\%)$ \\
\hline $\mathbf{1}$ & 25 & 80 & 53 & - & 33 & 14 \\
\hline $\mathbf{2}$ & 42 & 80 & 22 & - & 71 & 7 \\
\hline $\mathbf{3}$ & 42 & 100 & 22 & - & 52 & 26 \\
\hline $\mathbf{4}$ & 25 & 150 & 25 & - & 75 & - \\
\hline $\mathbf{5}$ & 42 & 150 & 12 & 13 & 40 & 35 \\
\hline $\mathbf{6}$ & 62 & 150 & 8 & 2 & 58 & 32 \\
\hline $\mathbf{7}$ & 125 & 150 & - & $\leq 1$ & 53 & 47 \\
\hline
\end{tabular}

After the first attempts at $80{ }^{\circ} \mathrm{C}$ (Table 3 , entry 1), it became clear that the poor formation of 10 was caused by hydrolysis of the reactive chloride in the presence of traces of moisture. The formation of the undesired acid 11 and anhydride 12 was confirmed by ${ }^{1} \mathrm{H}$ and ${ }^{31} \mathrm{P}$ NMR analysis. Re-drying of toluene and prolonging the residence time to $42 \mathrm{~min}$ resulted in a higher conversion, but led to more side-product 11 formation (entry 2). Rising the reaction temperature up to $150{ }^{\circ} \mathrm{C}$ improved the conversion into 10 only to $13 \%$ for 42 min of residence time (Table 7, entry 5). Interestingly, further studies have shown that reactions with a longer residence time of 62 and $125 \mathrm{~min}$ and a temperature of $150{ }^{\circ} \mathrm{C}$, allowed to obtain higher conversions of 9, but the amount of desired product was negligible (Table 3, entries 6-7).

Based on our experimental results, computational mechanistic studies were conducted to understand the chlorination reaction, especially the role of $\mathrm{CCl}_{4}$ as previously proposed. 


\section{Theoretical section \\ Considered mechanism}

Phosphine oxide - phosphinous acid tautomerisation<smiles>[R][PH]([R2])O</smiles>

Scheme 4. Tautomerization of secondary phosphine oxide (left) $P(V)$, to phosphinous acid (right) $\mathrm{P}(\mathrm{III})$.

It is known that pentavalent phosphine oxides undergo reversible tautomeric conversion to its corresponding trivalent phosphinous acid (scheme 4). The previous comparison of experimental and ab initio predicted absorption and VCD spectra has indicated that only one tautomeric structure - the pentavalent one - is predominant for phosphine oxide 1 in $\mathrm{CHCl}_{3}$ solution ${ }^{[19]}$. However, the trivalent form is believed to be a very active compound in the mechanism of the reaction depicted in scheme 5 , where a nucleophilic attack of the trivalent phosphorus atom on the electropositive chlorine atom creates a complex 13 between the chloro-substituted phosphorus cation and the anion $\mathrm{CCl}_{3}{ }^{-[19]}$. The proton transfer-process takes place from the hydroxyl group to the carbanion with formation of final compoundsphosphinic chloride and chloroform.

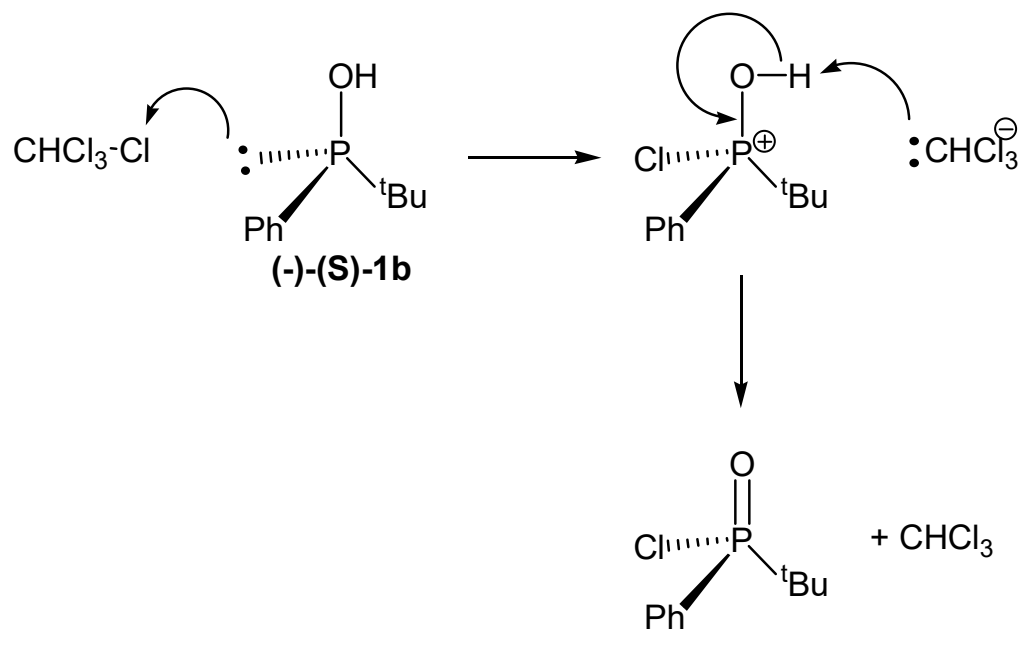

$(+)-(R)-3 b$

Scheme 5. The proposed mechanism of chlorination reaction with $\mathrm{CCl}_{4}$ as reported by Polavarapu et al.

There are however several points of dispute regarding this mechanism. Firstly, the phosphine oxide is much more thermodynamically stable and the equilibrium state of the reaction is significantly shifted to the left with an arguably very high energetic barrier between the two tautomers. This factor could significantly hamper the chlorination reaction, therefore, in order to estimate the tautomerisation barrier, the energy profile of the two types of conversion from pentavalent tert-butyl(phenyl)phosphine oxide (1) to its tautomeric trivalent form were examined. As previously proven for dimethylphosphine oxide, it can tautomerize to its trivalent form in two ways ${ }^{[37]}$. Route 1 - where one molecule of phosphine oxide is engaged in transferring a proton from its phosphorus atom to oxygen. Via this route, only one hydroxyphosphine molecule is formed at once from one molecule of oxide. Route 2 - where two molecules of oxide form a loosely bonded dimer, stabilized probably by $\pi-\pi$ stacking between the phenyl 
rings, can exchange their $\mathrm{P}-\mathrm{H}$ protons, in a cyclic transition state leading to two molecules of phosphine. Figure 1 depicts the transition states TS1.1 and TS1.2 of both routes. The transition states engaging more than two oxide molecules were not considered, assuming that the probability of such arrangement is statistically close to zero. (Gibbs free energy changes for various solvents and temperatures in case of tert-butyl(phenyl)phosphine oxide (1) are presented in table S1 supporting information.)<smiles></smiles>

TS1.1 (route 1)

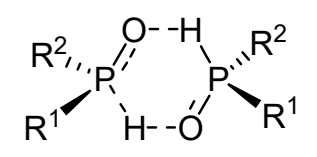

TS1.2 (route 2)
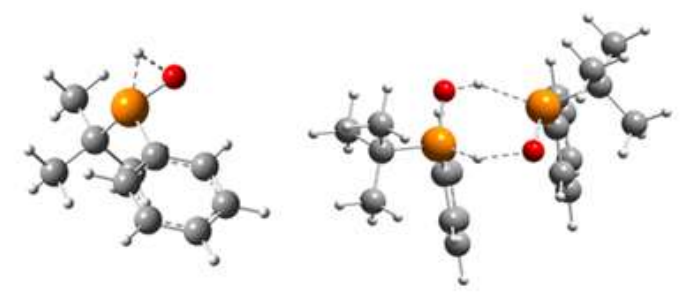

Figure 1. Two plausible routes of tautomerization of phosphine oxides 1-3. Breaking/forming bonds are marked with dashed lines. Structures TS1.1 and TS1.2 are visualized by GaussView6 software.

The energy barriers for route 2 are quite high, although significantly lower than for route 1 and slightly increase with the polarity of the solvent. This observation can be rationalized by invoking the fact that hydroxyphosphine is much less polar than the corresponding phosphine oxide and a proton transfer results in a decrease of the molecules dipole moment, which is energetically more disadvantageous in polar solvents. In each case, the applied temperature range had only little (ca. $1.5 \mathrm{kcal} / \mathrm{mol})$ impact on $\Delta G^{\ddagger}$. Such results are in accordance with the experiments since high yields of the chlorination reaction are obtained when the conditions are most suitable for the oxide-to-phosphine conversion. Using the same methodology, similar results were obtained for phosphine oxides 2 and $\mathbf{3}$. All tendencies are retained. The more polar the solvent is, the less favorable the formation of the phosphines becomes. The reaction barrier for the phenyl-substituted phosphines exhibit only a slight temperature dependence and bear a very close resemblance to the unsubstituted case. In the high temperatures range, route 1 could even gain a little on importance, but based on the calculations performed, route 2 is most probable as the primary mechanism for the phosphine oxide/hydroxyphosphine conversion. (table S2, S3 supporting information).

\section{hydroxyphosphine - phosphinyl chloride reaction}

The second question on the chlorination reaction is the role of $\mathrm{CCl}_{4}$. In view of the retention of configuration, this reagent can acts as an electropositive chlorine atom donor. However, our results showed that the first stage requires some clarification with regard to Polavarapus's mechanism. The quasiphosphonium salt 13 (scheme 5; must have been replaced by an intermediate pentacoordinate "P(V) compound" (scheme 6, figure 2). 


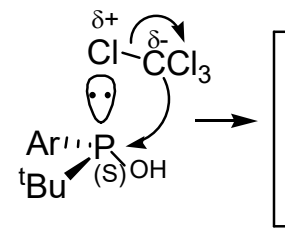

reactant complex

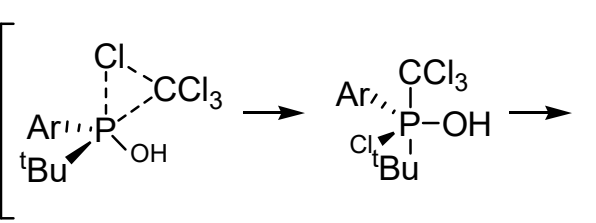

TS2.1

$\mathrm{P}(\mathrm{V})$ compound

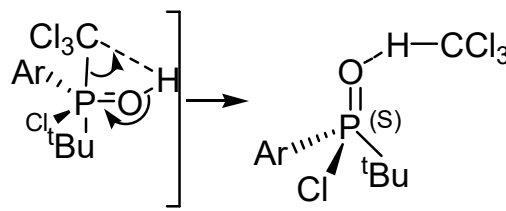

TS2.2 product complex

(retention)

Scheme 6. Suggested mechanism of action for $\mathrm{CCl}_{4}$.
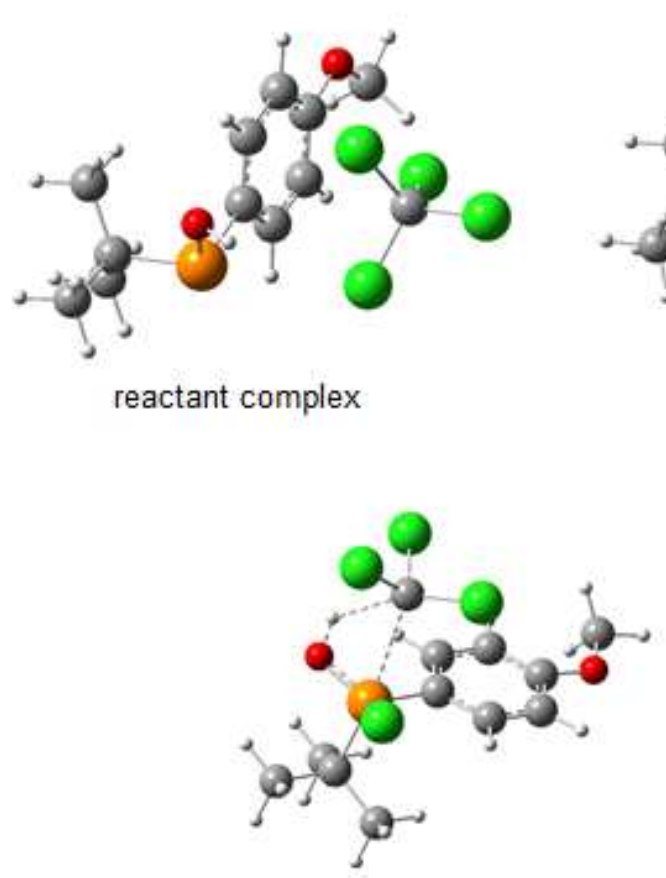

TS2 2

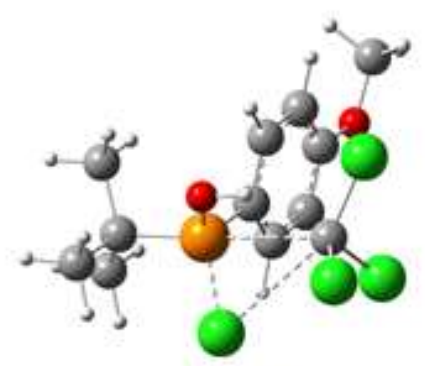

TS1 2

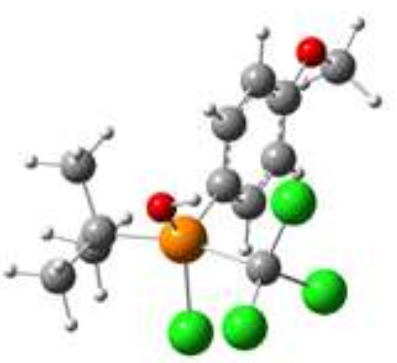

$P(V)$ compound

Figure 2. PES stationary point structures of reaction of 3 in toluene. Breaking/forming bonds and the hydrogen bond for product complex were marked with dashed lines. Structures visualized by

GaussView6 software.

The used theoretical method of the applied level did not support the hypothesis that proton transfer takes place when a free or complexed $\mathrm{CCl}_{3}{ }^{(-)}$carbanion is considered. None of such stationary points (minima or transition states) could be localized on the potential energy surface (PES). Our modified approach enabled us to propose the second stage, i.e. the detachment of the $\mathrm{CCl}_{3}$ group from the "P(V) compound" with simultaneous proton transfer from the hydroxyl group. The exemplary structures of PES stationary points of the chlorination reaction for compound 3 in toluene are shown in figure 2 (table S4 supporting information).

In the course of the reaction, the "reactant complex" - stabilized most probably by weak interaction between the lone pairs of the chlorine atoms and the phenyl ring's $\pi$ orbitals - is attacked by the lone pair of the phosphorus atom on one of the electropositive $\mathrm{CCl}_{4}$-chlorine atoms creating a slightly distorted, hypervalent $\mathrm{P}(\mathrm{V})$-trigonal bipiramidal structure. The $\mathrm{CCl}_{3}$-group is here in the apical position. The distortion from the ideal geometry is caused by steric hindrance of the bulky tert-butyl group and the chlorine substituents. Subsequent departure of that apical moiety with simultaneous proton transfer 
from the equatorial hydroxyl group (TS2.2) results in the formation of the "product complex" composed of phosphinyl chloride and chloroform. The final complex is in turn stabilized by a hydrogen bond between the phosphinic chloride oxygen atom lone pair and the proton of $\mathrm{CHCl}_{3}$. It is worth noting that TS2.1 from scheme 6 is not an as usual $S_{N} 2$-backside transition state, but rather a 'lateral' one in which one $\mathrm{C}-\mathrm{Cl}$ bond in $\mathrm{CCl}_{4}$ is loosened by the lone pair attack on the chlorine atom enabling simultaneously the phosphorus atom to accommodate (by expanding its coordination number) the nascent $\mathrm{CCl}_{3}$ group. The word attack should perhaps be even understood rather as an insertion of a lone pair between carbon and the chlorine atom, weakening the $\mathrm{C}$ - $\mathrm{Cl}$ bond by charge-transfer donation of electron density from the lone pair to the anti-bonding $\sigma_{C-C l}^{*}$ orbital than a nucleophilic attack on $\mathrm{Cl}$ sensu stricto. Although rather unusual, TS2.1 was the only one eventually found by the QST2 procedure ${ }^{[38]}$ and additionally, the internal reaction coordinate (IRC ${ }^{[39]}$ analysis confirms that PES minima called "reactant complex" and the "P(V) compound" are in fact connected by it. As previously mentioned - no other transition states capable of connecting the basins of the aforementioned minima or leading to a free or complexed $\mathrm{CCl}_{3}{ }^{(-)}$carbanion were localized. Moreover, there exist fully analogous reaction coordinate structures both for phosphine oxide $\mathbf{1}$ and $\mathbf{2}$. We therefore claim that such mechanism is plausible, despite its high energy barriers (supporting information tables S4-S6). The latter could be overcome by employing elevated temperatures and/or innovative laboratory techniques allowing high and efficient heat transfer as is precisely the case in the flow-setup. Our proposal for the formation of the three-membered transition state TS2.1 is further strengthened by Appel's hypotheses ${ }^{[40]}$. Appel suggested the formation of a similar transient state in the reactions of phosphine derivatives $\mathrm{R}_{3} \mathrm{P}$ with $\mathrm{CCl}_{4}$, only if $\mathrm{R}$ is not a strongly electron-donating group, otherwise the formation of an ionic form type $\mathbf{1 3}$ has been postulated. Based on literature data and our current research, we can conclude that the less nucleophilic the phosphorus atom is, the more likely it is to form a non-ionic intermediate (figure 3.). The monoalkyl phosphonate $\mathrm{R}(\mathrm{RO}) \mathrm{POH}$ is not reactive enough to function as productive nucleophile in the reaction with $\mathrm{CCl}_{4}$ but reacts with more active $\mathrm{CBr}_{4}$ without base [41-42]. Because dialkyl phosphites $(\mathrm{RO})_{2} \mathrm{POH}$ are even less reactive phosphorus species toward $\mathrm{CCl}_{4}$, the chlorination reaction only occurs in the presence of amines via the corresponding dialkyl phosphite anion $(\mathrm{RO})_{2} \mathrm{PO}-[43]$.

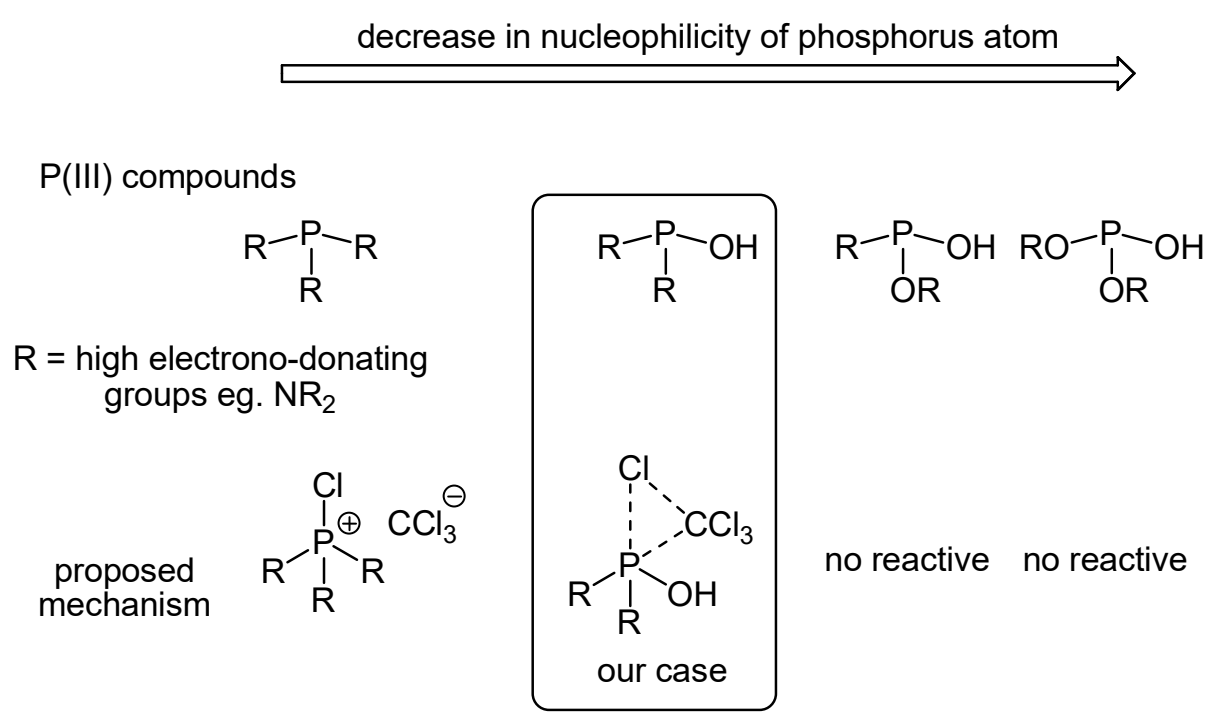

Figure 3. Comparison of the reactivity and the proposed intermediates for the reaction of different (PIII) compounds with $\mathrm{CCl}_{4}$ without the presence of a base.

Similarly as in the case of the tautomerization, the thermodynamics value from tables 4-6 (supporting information) are only minorly temperature - dependent and in various solvents the values $\Delta G^{\ddagger}$ and $\Delta G$ for the chlorination reaction are comparable. The impact of the solvent polarity on the overall course of 
the chlorination reaction should be considered in the context of two stages, I and II. As the calculations show, the formation of a less polar dimer TS1.2 will be preferred under non-polar conditions. Contrary to reaction I, reaction II proceeds effectively in more polar solvents. This can be explained by the fact that the resulting phosphinic chlorides are much more polar than the starting phosphines. Although, in view of the reaction mechanism, the non-polar " $P(V)$ compound" formed during the reaction prefers nonpolar conditions. Considering these three factors and based on the experimental results, the best yields of the total reaction (stages I and II) are in general obtained under conditions favoring elevated temperatures and low polarity solvents ( $\mathrm{CCl}_{4}$ and toluene).

We have excluded a mechanism involving a nucleophilic attack of the phosphine on $\mathrm{CCl}_{4}$ due to the results of an experiment with an optically active compound where we obtained a product with retention of configuration. The formation of a quasiphosphonium salt and a pentavalent phosphorus species with two most electronegative groups at the apical positions should finally lead to a phosphinic chloride with inversion (scheme 7).

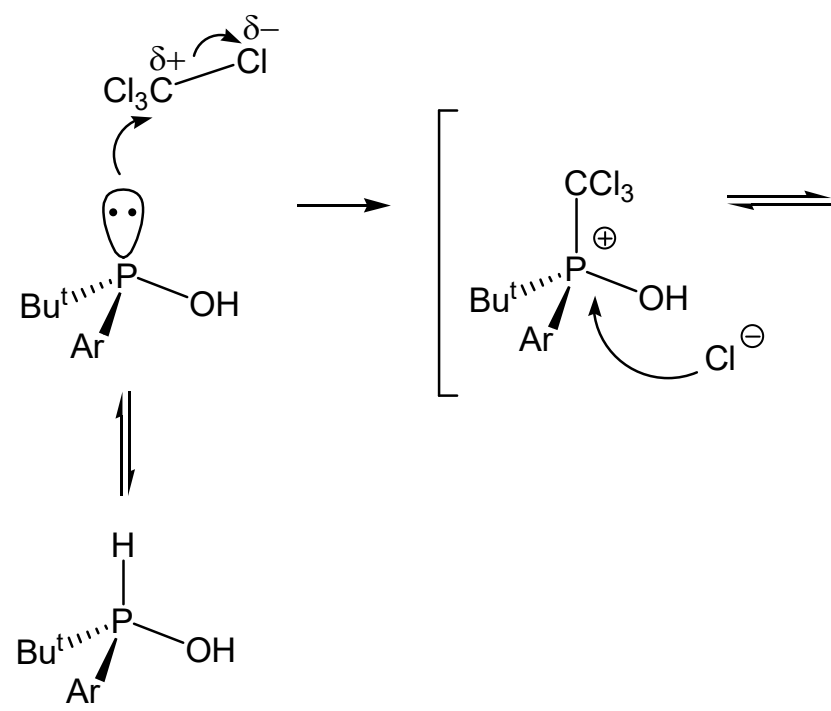

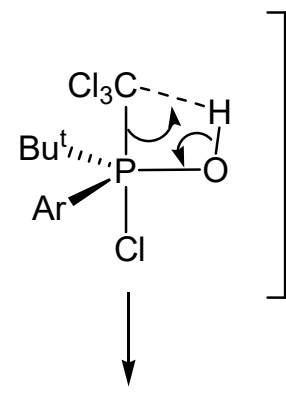<smiles>O=P([18O])([18F])[18F]</smiles>

inversion of configuration

Scheme 7. Alternative reaction mechanism of phosphine oxides 1-3 with $\mathrm{CCl}_{4}$ with inversion of configuration.

It is possible, in principle, to obtain a product with retention of configuration in this way. However, all attempts to find PES minima according to scheme 8 revealed that it is impossible (at least at the level of theory applied) to find any of the potential stable energetic minima corresponding to the presented structures. Such a result can be rationalized by a high steric congestion and unfavourable electrostatic interactions between the chlorine atom and the trichloromethyl group in the postulated transition states during pseudorotation. 


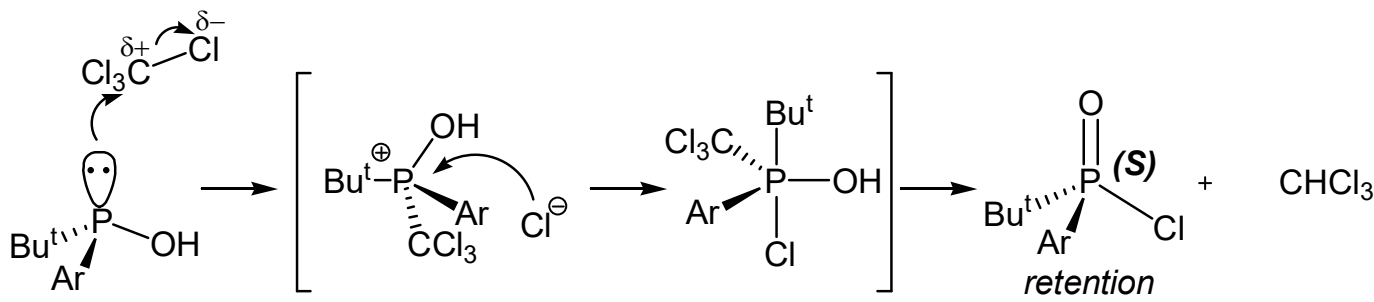

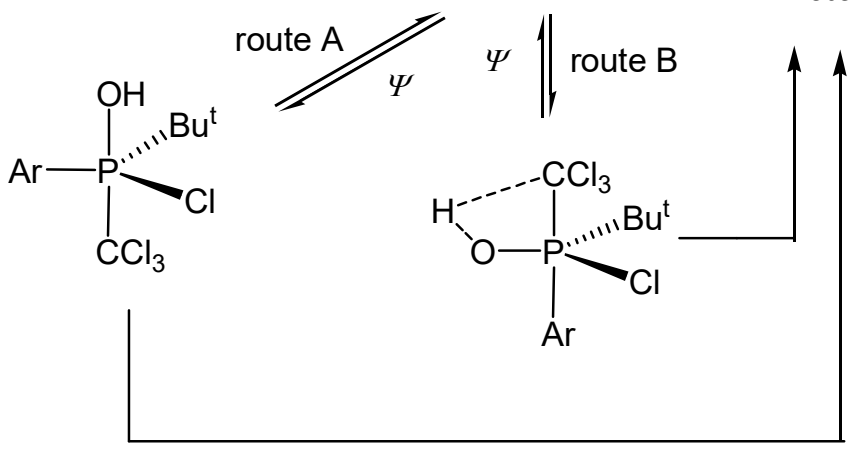

Scheme 8. Alternative mechanism of phosphine oxides 1-3 with $\mathrm{CCl}_{4}$ assuming pseudorotation process.

\section{Conclusion}

In exploring the chlorination process to poduce phosphinic chlorides, flow chemistry was found to give significant enhancements in reaction rates and yields compared to the corresponding batch processes. Selected phosphinic chlorides with at least one tert-butyl group 4, 5, 6, 8, can be simply prepared via halogenation of the corresponding $\mathrm{P}(\mathrm{O}) \mathrm{H}$ compounds with $\mathrm{CCl}_{4}$ under flow conditions. It was shown that mono-substituted tert-butyphosphine oxides 1-3 react with carbon tetrachloride with formation of the corresponding chlorides 4-6 in excellent conversions (up to $\geq 99 \%$ ), reasonable residence times (25$125 \mathrm{~min}$.) and in case of optically active compound $(R)-1$ a with high enantiomeric excess (96\%).

From our theoretical results, we showed that due to the unusually high energy barriers associated with the rate-determining step of the chlorination reaction and the tautomerization process, the high yields in the above-discussed reactions can be achieved under certain conditions: 1) moderate temperature and long-time batch reactions, 2) raised temperature and relatively short-time batch reactions, 3) raised temperature and short-time reactions using a highly sufficient heat-transfer method (flow chemistry). Therefore, it appears flow chemistry is the most appropriate method to produce the chloride purely under mild reaction conditions. In case of phosphine oxides, the steric hindrance induced by tert-butyl group is necessary to make this attempt successful.

We also demonstrated that the hitherto-postulated mechanism of such synthesis demands a revision in order to be reconcilable with the obtained theoretical data. It can now be postulated that: 1) the formation of the reactive trivalent tautomer of phosphine oxide takes place in a concerted transition state where two phosphine oxide molecules interchange their protons simultaneously, 2) the tetravalent quasiphosphonium salt is not a transition state of this reaction, 3) the rate-determining step of the chlorination reaction is the formation of a hypervalent, pentacoordinate phosphorus intermediate that subsequently undergoes further transformation to the reaction products. In accordance with experimental and theoretical data, the alternative mechanistic paths with electrophilic $\mathrm{CCl}_{4}$ could be excluded.

\section{Experimental section}

Liquid reagents were used in neat form and, if necessary, distilled prior to use. The continuous flow reactions were performed using a fully automated microreactor Asia 120 System (Syrris) (Table S7) fitted with a glass microreactor chip of $250 \mu \mathrm{l}$ internal volume and $1 \times 100 \mu \mathrm{l}$, and $1 \times 50 \mu \mathrm{l}$ syringes 
(ILS). The reactions were performed at temperatures up to $150^{\circ} \mathrm{C}$ using an Asia Heater. To prevent the formation of gas bubbles in the microreactor chip during reactions at high temperatures, pressure of 10 barg was used because the temperatures of the reactions in most cases exceeded the boiling points of solvents at standard conditions.

Barg refers to the gauge pressure, a relative pressure when the reference is atmospheric pressure (1 bar).

All reagents were purchased from Sigma-Aldrich except: racemic and optically active $t$ butylphenylphosphine oxide (1, $(R)$-1a), $t$-butyl-para-trifluoromethylphenylphosphine oxide (2), $t$-butylpara-methoxyphenylphosphine oxide (3), and were used as received, if necessary, distilled prior to use.

\section{Synthetic procedures}

The microreactor was rinsed with acetone before use and allowed to dry. Subsequently, the microreactor was filled with the phosphine oxide dissolved in the corresponding solvent in the first pump and carbon tetrachloride in the second using flow rates of $200-250 \mu \mathrm{min}^{-1}$ for $5 \mathrm{~min}$. Finally, a mixture of reagents was pumped through the microreactor with a flow rate corresponding to an applied ratio and a residence time.

Selected approaches were performed using previously mixed reagents in a 1:1 eq. ratio, pumping these using a single syringe pump and appropriate flow rate.

After a steady state period ( $25 \mathrm{~min} .-125 \mathrm{~min}$. depending on the flow rate, total volume of $250 \mu \mathrm{l}$ ), a sample was collected to be analyzed by ${ }^{1} \mathrm{H},{ }^{31} \mathrm{P}$ NMR. Excess of solvent was evaporated using a vacuum evaporator for 1-2 min., and the crude product was analyzed by ${ }^{1} \mathrm{H},{ }^{31} \mathrm{P}$ NMR again. The ${ }^{1} \mathrm{H}$ and ${ }^{31} \mathrm{P}$ NMR spectra of all obtained phosphinyl chlorides are consistent with the data reported in the literature.

\section{tert-butyl-para-trifluoromethylphenylphosphine oxide (2)}<smiles>O=[PH2]c1ccc(C(F)(F)F)cc1</smiles>

To a solution of $p$-(trifluoromethyl)phenyl dichlorophosphine $(3.6 \mathrm{~g}, 14.5 \mathrm{mmol})$ in dry diethyl ether, the $2 \mathrm{M}$ solution of tert-buthylmagnesium chloride $(1.68 \mathrm{~g}$, $14.5 \mathrm{mmol})$ in diethyl ether was added under an argon atmosphere at $-30^{\circ} \mathrm{C}$. The mixture was stirred at room temperature for 12 hours. After refluxing the solution for 2 hours, the mixture was then cooled to $5^{\circ} \mathrm{C}$ and $6 \mathrm{M}$ aqueous $\mathrm{HCl}$ was added dropwise. The product was extracted with chloroform. The organic layer was washed with $0.7 \mathrm{M} \mathrm{NaOH}$ and water, dried over $\mathrm{MgSO}_{4}$ and concentrated under a reduced pressure.

White solid; yield: $90 \%(3.28 \mathrm{~g}) .{ }^{31} \mathrm{P} \mathrm{NMR}\left(81 \mathrm{MHz}, \mathrm{CDCl}_{3}\right) \delta(\mathrm{ppm})=45.7 .{ }^{19} \mathrm{~F}\left(188 \mathrm{MHz}, \mathrm{CDCl}_{3}\right) \delta$ $(\mathrm{ppm})=-62.6 .{ }^{1} \mathrm{H} \mathrm{NMR}\left(500 \mathrm{MHz}, \mathrm{CDCl}_{3}\right) \delta(\mathrm{ppm}) 1.17\left(\mathrm{~d}, 9 \mathrm{H},{ }^{3} \mathrm{~J}_{\mathrm{PH}}=17.1 \mathrm{~Hz}, \mathrm{C}\left(\mathrm{C}_{3}\right)_{3}\right), 7.21(\mathrm{~d}, 1 \mathrm{H}$, $\left.{ }^{1} \mathrm{JPH}_{\mathrm{PH}}=457.1 \mathrm{~Hz}, \mathrm{P}(\mathrm{O}) \mathrm{H}\right), 7.75-7.79(\mathrm{~m}, 2 \mathrm{H}, 2 \mathrm{ArH}), 7.79-7.86(\mathrm{~m}, 2 \mathrm{H}, 2 \mathrm{x} \mathrm{ArH}) .{ }^{13} \mathrm{C} \mathrm{NMR}(50 \mathrm{MHz}$, $\left.\mathrm{CDCl}_{3}\right) \delta(\mathrm{ppm})=21.9\left(\mathrm{~s}, \mathrm{C}\left(\underline{\mathrm{CH}}_{3}\right)_{3}\right), 30.8\left(\mathrm{~d},{ }^{1} \mathrm{JPC}=69.6 \mathrm{~Hz}, \underline{\mathrm{C}}\left(\mathrm{CH}_{3}\right)_{3}\right), 122.2\left(\mathrm{q},{ }^{1} \mathrm{~J} \mathrm{CF}=272.2 \mathrm{~Hz}, \mathrm{CF}_{3}\right)$, $125.3\left(\mathrm{dq},{ }^{3} \mathrm{~J}_{\mathrm{CP}}=6.3 \mathrm{~Hz},{ }^{3} \mathrm{~J}_{\mathrm{CF}}=3.6 \mathrm{~Hz}, 2 \mathrm{x}-m-\left(\mathrm{C}_{6} \mathrm{H}_{4} \mathrm{P}(\mathrm{O})\right), 130.6\left(\mathrm{q},{ }^{2} \mathrm{~J}_{\mathrm{CF}}=32.3 \mathrm{~Hz}, p-\left(\mathrm{C}_{6} \mathrm{H}_{4} \mathrm{P}(\mathrm{O})\right), 133.7\right.\right.$ $\left(\mathrm{d},{ }^{2} \mathrm{JPC}=19.0 \mathrm{~Hz}, 2 \times \mathrm{o}_{\mathrm{C}}\left(\mathrm{C}_{6} \mathrm{H}_{4} \mathrm{P}(\mathrm{O})\right), 143.1\left(\mathrm{~d},{ }^{1} \mathrm{~J}_{\mathrm{CP}}=14.7 \mathrm{~Hz}\right.\right.$, ipso- $\left(\mathrm{C}_{6} \mathrm{H}_{4} \mathrm{P}(\mathrm{O})\right)$.

MS (Cl): $[\mathrm{M}+1] 251.1$

\section{tert-butyl-para-methoxyphenylphosphine oxide (3)}<smiles>COc1ccc(P(=O)([18OH])c2ccccc2)cc1</smiles>

To a solution of $3.17 \mathrm{~g}(20 \mathrm{mmol})$ tert-butyldichlorophosphine in dry diethyl ether $(50 \mathrm{ml}), 4.23 \mathrm{~g}(20 \mathrm{mmol})$ of 4-methoxyphenylmagnesium bromide in dry THF was added under an argon atmosphere at $-30^{\circ} \mathrm{C}$. The mixture was stirred at this temperature for 2 hours and then the cooling bath was removed. The reaction was performed at room temperature for the next 12 hours. After refluxing the solution for 2 hours, the mixture was cooled to $5^{\circ} \mathrm{C}$ and $6 \mathrm{M}$ aqueous $\mathrm{HCl}$ was added dropwise. The product was extracted with chloroform. The organic layer was washed with $0.7 \mathrm{M}$ $\mathrm{NaOH} /$ water, dried over $\mathrm{MgSO}_{4}$ and concentrated under a reduced pressure.

White solid; yield: $95 \%(4.23 \mathrm{~g}) .{ }^{31} \mathrm{P} \mathrm{NMR}\left(81 \mathrm{MHz}, \mathrm{CDCl}_{3}\right) \delta(\mathrm{ppm})=47.1 .{ }^{1} \mathrm{H} \mathrm{NMR}\left(200 \mathrm{MHz}, \mathrm{CDCl}_{3}\right)$ $\delta(\mathrm{ppm})=1.10\left(\mathrm{~d}, 9 \mathrm{H},{ }^{3} \mathrm{~J}_{\mathrm{PH}}=17.1 \mathrm{~Hz}, \mathrm{C}\left(\mathrm{CH}_{3}\right) 3\right), 3.83\left(\mathrm{~s}, 3 \mathrm{H}, \mathrm{OCH}_{3}\right), 6.96\left(\mathrm{~d}, 1 \mathrm{H},{ }^{1} \mathrm{~J}_{\mathrm{PH}}=451.6 \mathrm{~Hz}\right.$, $\mathrm{P}(\mathrm{O}) \mathrm{H})$, 6.92-7.04 (m, 2H, 2x ArH), 7.50-7.66 (m, 2H, 2x ArH). ${ }^{13} \mathrm{C} \mathrm{NMR}\left(50 \mathrm{MHz}, \mathrm{CDCl}_{3}\right) \delta(\mathrm{ppm})=$ 
$22.1\left(\mathrm{~s}, \mathrm{C}\left(\underline{\mathrm{CH}}_{3}\right)_{3}\right), 30.7$ (d, $\left.{ }^{1} \mathrm{JPC}=70.4 \mathrm{~Hz}, \underline{\mathrm{C}}\left(\mathrm{CH}_{3}\right)_{3}\right), 53.9\left(\mathrm{~s}, \mathrm{OCH}_{3}\right), 112.8$ (d, ${ }^{2} \mathrm{JPC}=12.9 \mathrm{~Hz}, 2 \mathrm{x}$ o$\mathrm{C}_{6} \mathrm{H}_{4} \mathrm{P}(\mathrm{O})$ ), $118.5\left(\mathrm{~d},{ }^{1} \mathrm{JPC}=95.6 \mathrm{~Hz}\right.$, ipso- $\left.\mathrm{C}_{6} \mathrm{H}_{4} \mathrm{P}(\mathrm{O})\right), 131.3\left(\mathrm{~d},{ }^{3} \mathrm{JPC}_{\mathrm{PC}}=11.4 \mathrm{~Hz}, 2 \mathrm{x} m-\mathrm{C}_{6} \mathrm{H}_{4} \mathrm{P}(\mathrm{O})\right), 163.9$ $\left(\mathrm{s}, p-\mathrm{C}_{6} \mathrm{H}_{4} \mathrm{P}(\mathrm{O})\right)$.

MS (Cl): [M+1] 213.1.

tert-butyl-phenylphosphinyl chlorides 4 and $(S)-4$<smiles>O=P(Cl)(Cl)c1ccccc1</smiles>

White solid. $[\alpha]_{D}{ }^{25}=-23.0$ (benzene, $c=0.910$ ), ee $=96 \%$.

${ }^{31} \mathrm{P} \mathrm{NMR}\left(81 \mathrm{MHz}, \mathrm{CDCl}_{3}\right) \delta(\mathrm{ppm})=74.1 .{ }^{1} \mathrm{H} \mathrm{NMR}\left(500 \mathrm{MHz}, \mathrm{CDCl}_{3}\right) \delta(\mathrm{ppm})=1.28$ $\left(\mathrm{d}, 9 \mathrm{H},{ }^{3} \mathrm{JPH}_{\mathrm{PH}}=18.0 \mathrm{~Hz}, \mathrm{C}\left(\mathrm{CH}_{3}\right)_{3}\right), 7.46-7.52(\mathrm{~m}, 2 \mathrm{H}, 2 \mathrm{x} \mathrm{ArH}), 7.59-7.62(\mathrm{~m}, 1 \mathrm{H}, \mathrm{ArH})$, 7.84-7.88 (m, 2H, 2xArH). ${ }^{13} \mathrm{C} \mathrm{NMR}\left(50 \mathrm{MHz}, \mathrm{CDCl}_{3}\right) \delta(\mathrm{ppm})=22.8\left(\mathrm{~s}, \mathrm{C}\left(\underline{\mathrm{C}} \mathrm{H}_{3}\right)_{3}\right)$, $39.0\left(\mathrm{~d},{ }^{1} \mathrm{JPC}=78.4 \mathrm{~Hz}, \underline{\mathrm{C}}\left(\mathrm{CH}_{3}\right)_{3}\right), 128.4\left(\mathrm{~d},{ }^{2} \mathrm{JPC}=12.4 \mathrm{~Hz}, 2 \mathrm{x} 0-\mathrm{C}_{6} \mathrm{H}_{4} \mathrm{P}(\mathrm{O})\right), 129.8(\mathrm{~d}$, ${ }^{1} \mathrm{JPC}=102.8 \mathrm{~Hz}$, ipso- $\left.\mathrm{C}_{6} \mathrm{H}_{4} \mathrm{P}(\mathrm{O})\right), 132.1\left(\mathrm{~d},{ }^{3} \mathrm{JPC}_{\mathrm{PC}}=2.1 \mathrm{~Hz}, 2 \mathrm{x} m-\mathrm{C}_{6} \mathrm{H}_{4} \mathrm{P}(\mathrm{O})\right), 132.6\left(\mathrm{~s}, p-\mathrm{C}_{6} \mathrm{H}_{4} \mathrm{P}(\mathrm{O})\right.$ ). HRMS calculated for $\mathrm{C}_{10} \mathrm{H}_{14} \mathrm{ClOP}=217.0549$, found 217.0552.

\section{(-)-(S)-tert-butylphenylphosphinyl chloride (4) (batch)}

To a solution of $0.045 \mathrm{~g}(0.2469 \mathrm{mmol})$ of $(+)-(R)-t-b u t y / p h e n y l p h o s p h i n e ~ o x i d e ~ 1 \mathrm{a},[\alpha]_{\mathrm{D}}+31(\mathrm{c}=20.0$, chloroform), in $0.88 \mathrm{ml}$ of anhydrous toluene, a solution of dry carbon tetrachloride $0.023 \mathrm{ml}(0.2469$ $\mathrm{mmol}$ ) was added. The reaction mixture was stirred at $100^{\circ} \mathrm{C}$ for 3 hours, after which ${ }^{31} \mathrm{P}$ NMR analysis of the reaction mixture indicated the complete disappearance of the starting phosphine oxide. Evaporation of the solvent gave a crude product, which was purified by column chromatography. (-)-(S)$t$-buty/phenylphosphinyl chloride, ee $=93 \%,[\alpha]_{D}{ }^{25}=-28.5$ (benzene, $c=1.0$ ) isolated by column chromatography Chiralcel OD-H, $5 \% \mathrm{iPrOH}$ in hexane, $0.5 \mathrm{ml} / \mathrm{min}, \mathrm{t}_{\mathrm{R}}[\mathrm{min}]=$.20.5 .

tert-butyl-para-trifluoromethylphenylphosphinyl chloride (5)<smiles>O=P(Cl)(Cl)c1ccc(C(F)(F)F)cc1</smiles>

${ }^{1} \mathrm{H}$ NMR $\left(500 \mathrm{MHz}, \mathrm{CDCl}_{3}\right) \delta(\mathrm{ppm})=1.24\left(\mathrm{~d}, 9 \mathrm{H},{ }^{3} \mathrm{JPH}_{\mathrm{PH}}=18.9 \mathrm{~Hz}, \mathrm{C}\left(\mathrm{CH}_{3}\right)_{3}\right)$, 6.98-7.03 (m, 2H, 2xArH), 7.76-7.83 (m, 2H, 2xArH). ${ }^{13} \mathrm{C}$ NMR (125 MHz, $\left.\left.\mathrm{CDCl}_{3}\right) \delta(\mathrm{ppm})=24.1\left(\mathrm{~s}, \mathrm{C}\left(\underline{\mathrm{CH}}_{3}\right)_{3}\right), 39.1\left(\mathrm{~d},{ }^{1} \mathrm{JPC}=78.3 \mathrm{~Hz}, \underline{\mathrm{C}}\left(\mathrm{CH}_{3}\right)_{3}\right)\right), 125.2$ $\left(\mathrm{dq},{ }^{3} \mathrm{~J}_{\mathrm{CP}}=6.3 \mathrm{~Hz},{ }^{3} \mathrm{~J}_{\mathrm{CF}}=3.6 \mathrm{~Hz}, 2 \mathrm{x} m-\left(\mathrm{C}_{6} \mathrm{H}_{4} \mathrm{P}(\mathrm{O})\right), 125.5\left(\mathrm{q},{ }^{1} \mathrm{~J}_{\mathrm{FC}}=274.1 \mathrm{~Hz}\right.\right.$, $\left.\mathrm{CF}_{3}\right), 128.6\left(\mathrm{q},{ }^{2} \mathrm{~J}_{\mathrm{CF}}=32.3 \mathrm{~Hz}, p-\left(\mathrm{C}_{6} \mathrm{H}_{4} \mathrm{P}(\mathrm{O})\right), 133.2\left(\mathrm{~d},{ }^{2} \mathrm{~J}_{\mathrm{PC}}=19.0 \mathrm{~Hz}, 2 \mathrm{x} o-\right.\right.$ $\left(\mathrm{C}_{6} \mathrm{H}_{4} \mathrm{P}(\mathrm{O})\right), 134.1\left(\mathrm{~d},{ }^{1} \mathrm{JPC}_{\mathrm{PC}}=14.7 \mathrm{~Hz}\right.$, ipso- $\left(\mathrm{C}_{6} \mathrm{H}_{4} \mathrm{P}(\mathrm{O}) .{ }^{31} \mathrm{P} \mathrm{NMR}\left(202 \mathrm{MHz}, \mathrm{CDCl}_{3}\right) \delta(\mathrm{ppm})=69.1\right.$.

${ }^{19} \mathrm{~F} \mathrm{NMR}\left(188 \mathrm{MHz}, \mathrm{CDCl}_{3}\right) \delta(\mathrm{ppm})=-62.7$.

HRMS calculated for $\mathrm{C}_{11} \mathrm{H}_{13} \mathrm{ClF}_{3} \mathrm{OP}=285.0423$, found 285.0427 .

\section{tert-butyl-para-methoxyphenylphosphinyl chloride (6)}

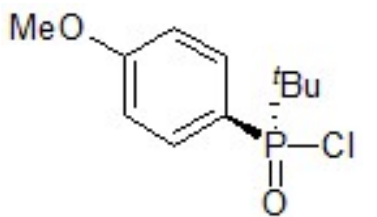

${ }^{1} \mathrm{H}$ NMR $\left(500 \mathrm{MHz}, \mathrm{CDCl}_{3}\right) \delta(\mathrm{ppm})=1.22\left(\mathrm{~d}, 9 \mathrm{H},{ }^{3} \mathrm{JPH}_{\mathrm{PH}} 18.7 \mathrm{~Hz}, \mathrm{C}\left(\mathrm{C}_{3}\right)_{3}\right), 3.85$ (s, 3H, OCH 3 ), 6.92-7.04 (m, 2H, 2xArH), 7.69-7.85 (m, 2H, 2xArH). ${ }^{13} \mathrm{C} \mathrm{NMR}$ $\left(125 \mathrm{MHz}, \mathrm{CDCl}_{3}\right) \delta(\mathrm{ppm})=24.5\left(\mathrm{~s}, \mathrm{C}\left(\underline{\mathrm{CH}}_{3}\right)_{3}\right), 33.1\left(\mathrm{~d},{ }^{1} \mathrm{JPC}=70.7 \mathrm{~Hz}\right.$, $\left.\left.\underline{\mathrm{C}}\left(\mathrm{CH}_{3}\right)_{3}\right)\right), 56.4\left(\mathrm{~s}, \mathrm{OCH}_{3}\right), 115.2\left(\mathrm{~d},{ }^{2} \mathrm{JPC}=12.3 \mathrm{~Hz}, 2 \mathrm{x} o-\mathrm{C}_{6} \mathrm{H}_{4} \mathrm{P}(\mathrm{O})\right), 120.8(\mathrm{~d}$, ${ }^{1} \mathrm{JPC}=96.7 \mathrm{~Hz}$, ipso- $\left.\mathrm{C}_{6} \mathrm{H}_{4} \mathrm{P}(\mathrm{O})\right), 133.7\left(\left(\mathrm{~d},{ }^{3} \mathrm{JPC}=12.0 \mathrm{~Hz}, 2 \mathrm{x} m-\mathrm{C}_{6} \mathrm{H}_{4} \mathrm{P}(\mathrm{O})\right)\right.$, $163.9\left(\mathrm{~s}, p-\mathrm{C}_{6} \mathrm{H}_{4} \mathrm{P}(\mathrm{O}) .{ }^{31} \mathrm{P} \mathrm{NMR}\left(81 \mathrm{MHz}, \mathrm{CDCl}_{3}\right) \delta(\mathrm{ppm})=71.8\right.$. HRMS calculated for $\mathrm{C}_{11} \mathrm{H}_{16} \mathrm{ClO}_{2} \mathrm{P}=247.0662$, found 247.0656 . 
${ }^{1} \mathrm{H}$ NMR $\left(200 \mathrm{MHz}, \mathrm{CDCl}_{3}\right) \delta(\mathrm{ppm})=1.38\left(\mathrm{~d}, 18 \mathrm{H},{ }^{3} \mathrm{JPH}=17.0 \mathrm{~Hz}, 2 \times \mathrm{P}(\mathrm{O})\left(\mathrm{CC}_{\mathrm{H}}\right)_{3}\right)$.

${ }^{13} \mathrm{C} \mathrm{NMR}\left(125 \mathrm{MHz}, \mathrm{CDCl}_{3}\right) \delta(\mathrm{ppm})=41.6\left(\mathrm{~d},{ }^{1} \mathrm{JPC}=61.4 \mathrm{~Hz}, \underline{\mathrm{C}}\left(\mathrm{CH}_{3}\right)_{3}\right), 26.7(\mathrm{~s}$,

$\left.\mathrm{P}(\mathrm{O})\left(\mathrm{C}_{\mathrm{C}} \mathrm{H}_{3}\right)_{3}\right) .{ }^{31} \mathrm{P} \mathrm{NMR}\left(202 \mathrm{MHz}, \mathrm{CDCl}_{3}\right) \delta(\mathrm{ppm})=94.7$.

HRMS calculated for $\mathrm{C}_{8} \mathrm{H}_{18} \mathrm{ClOP}=197.0863$ found 197.0862 .

\section{Theoretical section}

All the structures were optimized using the density functional theory as implemented in the Gaussian 16 software. Due to the lack of any previous functional benchmark, APFD/6-311+G(d,p) was used as the optimization method as proposed by Gaussian 16 developers [34]. More accurate single-point energies were computed using the APFD/mg3s//APFD/6-311+G(d,p) level of theory (mg3s [35] is a modified Pople's $6-311++G^{* *}$ triple-zeta basis set with polarization functions added to all heavy atoms).

All geometries were confirmed to be appropriate potential energy surface (PES) stationary points (i.e. minima and transition states) by frequency calculation. Thermal corrections for enthalpy and entropy contributions at the applied temperature ranges were provided by vibrational analysis within the rigid rotor/harmonic oscillator/ideal gas approximation [34]; the scaling factor was chosen to be 0.98 . The solvent was modeled only by continuous model (PCM) approximation (no more elaborate methods like SMD [36] were applied for calculating the free energy of solvation $\Delta G_{\text {solv }}$ ).

Total changes of reaction Gibbs free energy at a given temperature $-\Delta G^{\text {temp }}$ and the reaction barrier heights $-\Delta G^{\ddagger}$ were computed by the most rudimentary scheme as the difference between the sum of free energy of the products and the sum of free energy of the reactants in the solvent - eq. (1)-(3).

$$
\begin{gathered}
G_{i}^{\text {temp }}=E_{i}^{\text {electr }}+d G_{i}^{\text {temp }} \\
\Delta G_{i}^{\text {temp }}=G_{i}^{\text {temp }}-\sum_{j}^{\text {free substrates }} G_{j}^{\text {temp }} \\
\Delta G^{\text {temp }}=\sum_{k}^{\text {free products }} G_{k}^{\text {temp }}-\sum_{j}^{\text {free substrates }} G_{j}^{\text {temp }}
\end{gathered}
$$

Symbols used in these equations mean:

eq. (1) $-G_{i}^{\text {temp }}$ is the calculated free energy of $i$-th species, be it substrate or product, at a given temperature; $E_{i}^{\text {electr }}=$ its APFD/mg3s//APFD/6-311+G(d,p) electronic energy; $d G_{i}^{\text {temp }}$ is the thermal correction to the electronic energy at a given temperature obtained from vibrational analysis;

eq. (2) $-\Delta G_{i}^{\text {temp }}=$ the free energy change of $i$-th species relative to the sum of the substrates free energy which was adopted as reference point in the calculation of $\Delta G_{i}-$ calculating $\Delta G^{\ddagger}$ is an exemplary case, where $\mathrm{G}_{\mathrm{i}}=\mathrm{G}_{\mathrm{TS}}$;

eq. (3) $-\Delta G^{\text {temp }}$ is the total reaction Gibbs free energy change at a given temperature.

\section{Association Content}

\section{Supporting Information}

Supporting Information available. Segmental experiment data, ${ }^{1} \mathrm{H},{ }^{31} \mathrm{P},{ }^{13} \mathrm{C}$ and ${ }^{19} \mathrm{~F}$ NMR data for all compounds are provided. The Supporting Information is available free of charge on the ACS Publication website at DOI: $\mathrm{xxx}$

\section{Author Information}

\section{Corresponding Author}

*E-mail: draj@cbmm.lodz.pl (J. Drabowicz), E-mail: ajasiak@cbmm.lodz.pl (A.Jasiak) 


\section{ORCID}

Józef Drabowicz: 0000-0002-4899-5970

Aleksandra Jasiak: 0000-0003-1570-5372

\section{Acknowledgement}

The project was financed by the National Science (NCN), Poland on the basis of the decision number UMO-2014/15/B/ST5/05329.

\section{References and Endnotes}

[1] K.M. Pietrusiewicz, M. Zabłocka, Chem. Rev., 1994, 9, 1375.

[2] D. Hẻrault, D. H. Nguyen, D. Nuel, G. Buono, Chem. Soc. Rev., 2015, 44, 2508-2523.

[3] N. Z. Kiss, G. Keglevich, Curr. Org. Chem., 2014, 18 (21), 2673-2690.

[4] Y. Zhou, G. Wang, Y. Saga, R. Shen, M. Goto, Y. Zhao, L. B. Han, J. Org. Chem., 2010, 75, 79247927.

[5] R. Nallagonda, N. Thrimurtulu, Ch. M. R. Volla, Adv. Synth. Catal., 2018, 360, 255-260.

[6] M. A. del Ảguila-Sánchez, N. M. Santos-Bastos, M. C. Ramalho-Freitas, J. G. López, M. Costa de Souza, J. A. L. Camargos-Resende, M. Casimiro, G. Alves-Romeiro, M. J. Iglesias, F. López Ortiz, Dalton Trans., 2014, 43, 14079-14091.

[7] D. L. J. Clive, S. Kang, J. Org. Chem., 2001, 66, 6083-6091.

[8] M. Oliana, F. King, P. N. Horton, M. B. Hursthouse, K. K. Hii, J. Org. Chem., 2006, 71 (6), 24722479.

[9] M. Yuan, I. I. Mbaezue, Z. Zhou, F. Topic, Y. S. Tsantrizos, Org. Biomol. Chem., 2019, 17, 86908694.

[10] M. Hatano, T. Miyamoto, K. Ishihara, Org. Lett., 2007, 9, 22, 4535-4538.

[11] P. Schrögel, M. Hoping, W. Kowalsky, A. Hunze, G. Wagenblast, Ch. Lennartz, P. Strohriegl, Chem. Mater., 2011, 23, 22, 4947-4953.

[12] L. Liu, A-A. Zhang, Y. Wang, F. Zhang, Z. Zuo, W-X. Zhao, C-L. Feng, W. Ma, Org. Lett., 2015, 17, 9, 2046-2049.

[13] L. A. Reiter, B. P. Jones, J. Org. Chem., 1997, 62 (9), 2808-2812.

[14] W. W. Metcalf, W. A. van der Donk, Annu Rev Biochem., 2009, 78, 65-94.

[15] A. A. Sayed, A. Simeonov, C. J., Thomas, J. Inglese, Ch. P. Austin, D. L. Williams, Nat. Med., 2018, $14(4), 407-412$.

[16] M. M. Abdou, P. M. O’Neill, E. Amigues, M. Matziari, Drug Discovery, 2019, 24 (3), 916-929.

[17] M. D. Sørensen, L. K. A. Blæhr, M. K. Christensen, T. Høyer, S. Latini, P.-J. V. Hjarnaa, F. Björkling, Bioorg. Med. Chem., 2003, 11, 5461-5484.

[18] W. J. Moree, G. A. van der Marel, J. H. van Boom, R. M. J. Liskamp, Tetrahedron, 1993, 49 (47), 11055-11064.

[19] F. Wang, P. L. Polavarapu, J. Drabowicz, M. Mikołajczyk, J. Org. Chem., 2000, 65, 7561-7565.

[20] B. A. Trofimov, N. K. Gusarova, P. A. Volkov, N. I. Ivanova, K. O. Khrapova, Heteroat. Chem., 2016, 27 (1), 44-47.

[21] S. S. Le Corre, M. Berchel, H. Couthon-Gourvès, J. P. Haelters, P. A. Jaffrès, Beilstein J. Org. Chem., 2014, 10, 1166-1196.

[22] Y. Ou, Y. Huang, Z. He, G. Yu, Y. Huo, X. Li, Y. Gao, Q. Chen, Chem. Commun., 2020, 56, 13571360.

[23] Y. Zhou, G. Wang, Y. Saga, R. Shen, M. Goto, Y. Zhao, L. B. Han, J. Org. Chem., 2010, 75, 79247927.

[24] J. Eljo, G. K. Murphy, Tetrahedron Lett., 2018, 59, 2965-2969.

[25] E. Müller, H. G. Padeken, Chem. Ber., 1967, 100, 521-532.

[26] M. J. P. Harger, A. Smith, J. Chem. Soc., Perkin Trans., 1990, 1447-1451.

[27] V. Kumar, M. P. Kaushik, Chem. Lett., 2006, 35 (3), 312-313.

[28] B. Kaboudin, A. Donyavi, F. Kazemi, Synthesis, 2018, 50 (01), 170-174. 
[29] G. W. Kenner, A. R. Todd, F. J. Weymouth, J. Chem. Soc., 1952, 3675-3681.

[30] F. R. Atherton, H. T. Openshaw, A. R. Todd, J. Chem. Soc., 1945, 660-663.

[31] V. Mitova, N. Koseva, K. Troev, RSC. Adv., 2014, 4, 64733.

[32] C. G. E. Fleming, A. M. Z. Slawin, K. S. Athukorala Arachchige, R. Randall, M. Bühl, P. Kilian, Dalton Trans., 2013, 42, 1437-1450.

[33] A. Jasiak, G. Mielniczak, K. Owsianik, M. Koprowski, D. Krasowska, J. Drabowicz, J. Org. Chem., 2019, 84, 2619-2625.

[34] O. I. Kolodiazhnyi, Phosphorus, Sulfur and Silicon and the Relat. Elem., 2019, 194, 396-400.

[35] D. F. Brayton, K. I. Goldberg, W. Kaminsky, D. M. Heinekey, Phosphorus, Sulfur and Silicon and Relat. Elem., 2008, 183, 2534-2540.

[36] G. Aksnes, P. Majewski, Phosphorus and Sulfur and Silicon and Relat. Elem., 1986, 26, 261-274.

[37] D. Vinche, P. Bagi, P. Ảbrányi-Balogh, Phosphorus and Sulfur and Silicon and Relat. Elem., 2019, 194, 359-360.

[38] Ch. Peng, H. B. Schlegel, Isr. J. Chem., 1993, 33, 449-454.

[39] K. Fukui, Acc. Chem. Res., 1981, 14, 363-368.

[40] R. Appel, Angew. Chem. In. Ed., 1975, 14, 801-811.

[41] O. I. Kolodiazhnyi, E. V. Grishkun, Phosphorus and Sulfur and Silicon and Relat. Elem., 1995, 103, 191-197.

[42] B. Xiong, Y. Zhou, Ch. Zhao, M. Goto, S-F. Yin, L-B. Han, Tetrahedron, 2013, 69, 9373-9380.

[43] A. Kong, R. Engel, Bull. Chem. Soc. Jpn., 1985, 58, 3671-3672. 